\title{
QUANTITATIVE ANALYSIS OF DEFORMATION ALONG THE FAULT DAMAGE ZONE OF THE KLIMATIA THRUST (NW GREECE, IONIAN ZONE)
}

\author{
A. Kostakioti, P. Xypolias, S. Kokkalas and T. Doutsos \\ Department of Geology, University of Patras, 26500, Patras, Greece, p.xypolias@upatras.gr
}

\begin{abstract}
In this study, we present structural, fracture orientation and fracture density (FD) data in order to quantify the deformation pattern of a damage zone that form around the slip plane of a large scale thrust fault which is located on the Ionian zone (External Hellenides) in northwestern Greece. Structural analysis showed at least two major deformation stages as indicated by the presence of refolding, backthrusting and break-back faulting. The fracture orientation analysis revealed three main fracture systems, a dominant conjugate fracture system which is perpendicular to the transport direction (NW-to NNW trending sets), a conjugate fracture system trending parallel to the transport direction (ENE-trending conjugate sets) and a third diagonal conjugate fracture system (WNW and NNE trending sets). Resulting fracture density-distance diagrams display a decrease of total fracture density away from the studied fault, which is largely heterogeneous and irregular on both footwall and hanging wall. The conjugate fracture system trending perpendicular to the transport direction has the dominant contribution to the accumulation of total fracture density. Based on these results we suggest that the observed heterogeneous and irregular distribution of fracture density fashioned during the second deformation stage and is attributed to the formation of backthrusts and break-back thrust faults.
\end{abstract}

\section{INTRODUCTION}

In recent years, there is an increasing interest on field and laboratory studies dealing with the quantification of deformation of fault zones (e.g Newman and Mitra 1993; Billi et al., 2003, Kim et al., 2004; Du Bernard and Labaume 2002). In elasticofrictional regimes the architecture of a fault zone exhibits (a) a fault core zone which is defined by cataclasites and/or tectonic brecia and (b) a damage zone which is a zone of intense deformation and is identified in both footwall and hanging wall. The last may extend for hundreds of meters away from the master fault and is characterized by a population of subsidiary saults and fractures. Several authors emphasize that the calculation of fracture density (FD, fractures per meters) along scan lines perpendicular to fault strike is an accurate and efficient technique to quantify the deformation intensity as well as the width of a fault damage zone. Such studies have shown that fault zones exhibit a pattern of relatively undeformed pods of rock, bounded by anastomosing zones of strongly deformed rocks (Mitra and Ismat 2001, Mitra 1984, 1992, 1993; Chester and Logan 1986; Yonkee and Mitra 1993).

In Greece there are few studies dealing with the quantitative analysis and architecture of fault zones (Micarelli et al., 2003). The importance for studying the architecture of fault zones and especially the fault damage zones lies on the valuable information we can extract, such as fault propagation and growth (McGrath and Davison 1995; Kim et al., 2001a,b), fluid flow (Sibson 1996), permeability (Viruete et al., 2(01) and deformation history.

In this work we chose a thrust fault in order to quantify the deformation intensity across the fault and to define the damage zone width by calculating FD along scan lines perpendicular to fault strike within a background value. Moreover, we correlate the structural evolution to the FD distribution in order to discuss the mechanism of the deformation accumulation on the studied fault zone. 


\section{GEOLOGICAL SETTING}

The study area is located on the Ionian zone (External Hellenides) in northwestern Greece (Fig.1). In this area the following stratigraphic formations can be distinguished from bottom to top (Karakitsios, 1995): the Lower-Middle Lias Pantocrator limestones, the Upper Lias-Upper Jurassic Posidonian beds, the Upper Jurassic-Low Senonian Vigla limestones, the Upper Senonian Limestones with Roudistes, the Faleocene-Upper Eocene Sublithographic limestones, and the Upper Eocene-Burdigalian Flysch. We focused on the damage zone of a large scale thrust fault called hereafter Klimatia thrust, which crops out close to Klimatia village (Epirus area) in an excellent road cut trending normal to the fault strike. The Klimatia thrust is a NNW-SSE trending, ENE-dipping and approximately bedding-parallel fault with approximately $750 \mathrm{~m}$ throw. It places a thin slice of Upper Jurassic Posidonian Beds over the Lower Cretaceous Vigla limestones duplicating structurally the thickness of Lower Cretaceous carbonate rocks. The fault core is composed of $15 \mathrm{~m}$ thick cataclastic material derived mainly froin the soft Posidonian Beds (Fig. 2).

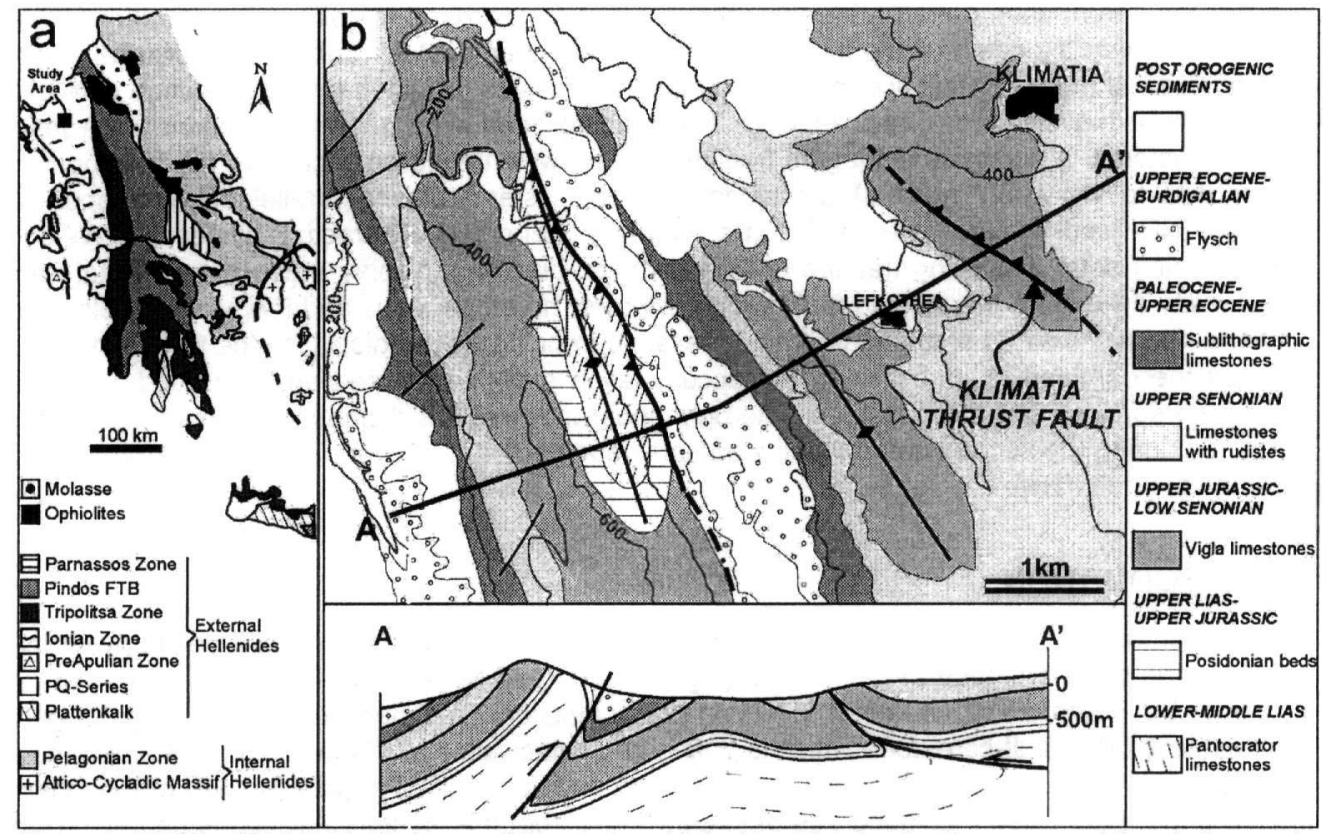

Figure 1. (a) Simplified geologiczl map of the western Hellenides showing isopic zones and the study area located on lonian zone. (b) Geological map of the study area and cross-section showing the major structural elements including the Klimatia thrust fault on which this work focuses. The displacement of Klimatia thrust fault is estimated approximately $750 \mathrm{~m}$.

\section{METHODOLOGY-DATA COLLECTION}

The applied methodology for this study includes mainly the calculation of FD and fracture orientation analysis. For the structural description of the damage zone we use the term fracture to include all elasticofrictional deformational features such as joints, solution cleavages and small-scale faults. In the field the differeniiation between damage zone and fault core was based on the recognition of ultracataclasites and cataclasites that are typical of fault cores. For the calculation of the FD we applied the scan line technique for $420 \mathrm{~m}$. The scan lines were simple measuring tapes, $2 \mathrm{~m}$ long, placed horizontally. Mean orientation of applied scan lines was $N 65^{\circ} \mathrm{E}$. Deviations in the scan lines were less than $10^{\circ}$ from a straight line, so there was a negligible influence on the scan line regime. The application of the scan line technique enabled us to estimate the FD and thus the fracture spacing. The calculation of the total FD was accomplished by measuring every fracture intersecting the scan line. Furthermore and after having identified the number and the representative 
orientation of fracture sets, which are responsible, for the fracturing of the wallrock we applied the trigonometric correction in order to estimate the normal set density.

The trigonometric correction is based on the simple theory that the real FD of a fracture set can be estimated only at a direction normal to the mean orientation of the set (Terzaghi, 1965, Priest, 1993). The trigonometric correction is based on the following equation:

$$
N t=N a / \cos (\theta)
$$

where, $N t$ is the number of fractures measured normal to the mean orientation of a fracture set, $N \alpha$ is the number of fractures of a set measured along a scan line of random orientation and $\theta$ is the angle between the scan line and the normal to the fracture set.

We also took orientation measurements of about 900 fractures in the field in order to obtain a clear image of the fracture network. Scaled photographs of the rock face and scan line, were also essential for our work. Great importance was given to the position of the camera with its lens axis normal to the face. We took 170 photographs of $1 \mathrm{~m}$ scale and 30 photographs of $10 \mathrm{~m}$ scale.

\section{DATA ANALYSIS}

\subsection{Mesoscopic structural description}

A schematic cross section perpendicular to Klimatia thrust fault is presented in Figure 2. In this WSW-ENE trending cross section the Upper Jurassic Posidonian beds thrust onto Vigla limestones. In the hanging wall the deforrnation is mainly expressed by subsidiary thrust faults (splays). These are mainly observed in the first $150 \mathrm{~m}$ away from the Klimatia thrust, while in the more distal positions slightly inclined beds occur. Bellow a major subsidiary fault, which is accompanied by a cataclastic zone, refolded limestone beds were recognized (Fig. 2, Fig. 3a). This enables us to assume at least two deformation events. In the hanging wall fold analysis indicates that all fold generations are co-axial with axes trending NNW-SSE (Fig. 3b). All folds show asymmetry towards WSW.

In the footwall, deformation is characterized mainly by folding. A major anticline is observed bellow the Klimatia thrust. At the west limb of this anticline a west dipping bedding parallel shear zone was detected (Fig. 2, Fig. 3c) supporting backward movements (eastwards). Fold analysis showed that the axes have a NW to NVW trend (Fig. 3b), similar to the hanging wall.

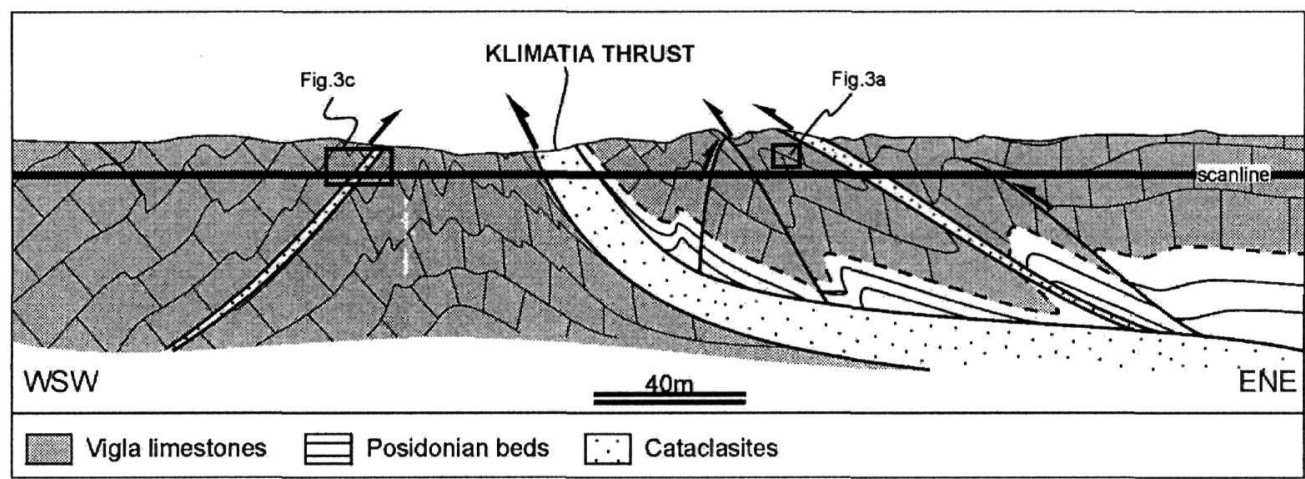

Figure 2. Cross section perpendicular to Klimatia thrust fault. Fault core zone is almost $15 \mathrm{~m}$. Posidonian beds thrust over Vigla limestones dupicating structurally the thickness of the carbonate rocks. In the hanging wall, deformation is mainly expressed by subsidiary thrust faults and in footwall mainly by folding.

\subsection{Fracture orientation data}

Along the cross section about 900 fractures were measured. The orientation measurements were projected on 4 stereonets (Fig. $4 a$ ). The strong similarity of these stereonets shows that the main fracture sets have constant orientation throughout the cross section. Based on the statistical analysis we identified three main fracture systems (Fig. 4b). The first fracture system includes the NW- to NNW trending conjugate sets 1 and 2, which are parallel to Klimatia thrust. This fracture system is associated with pressure solution cleavage. The second system includes the ENE- 
trending conjugate sets, 3 and 4, which are almost perpendicular to Klimatia thrust fault, and is associated with normal sense shearing. Finally, the third system includes the WNW and NNE conjugate sets 5 and 6 with almost vertical dips.
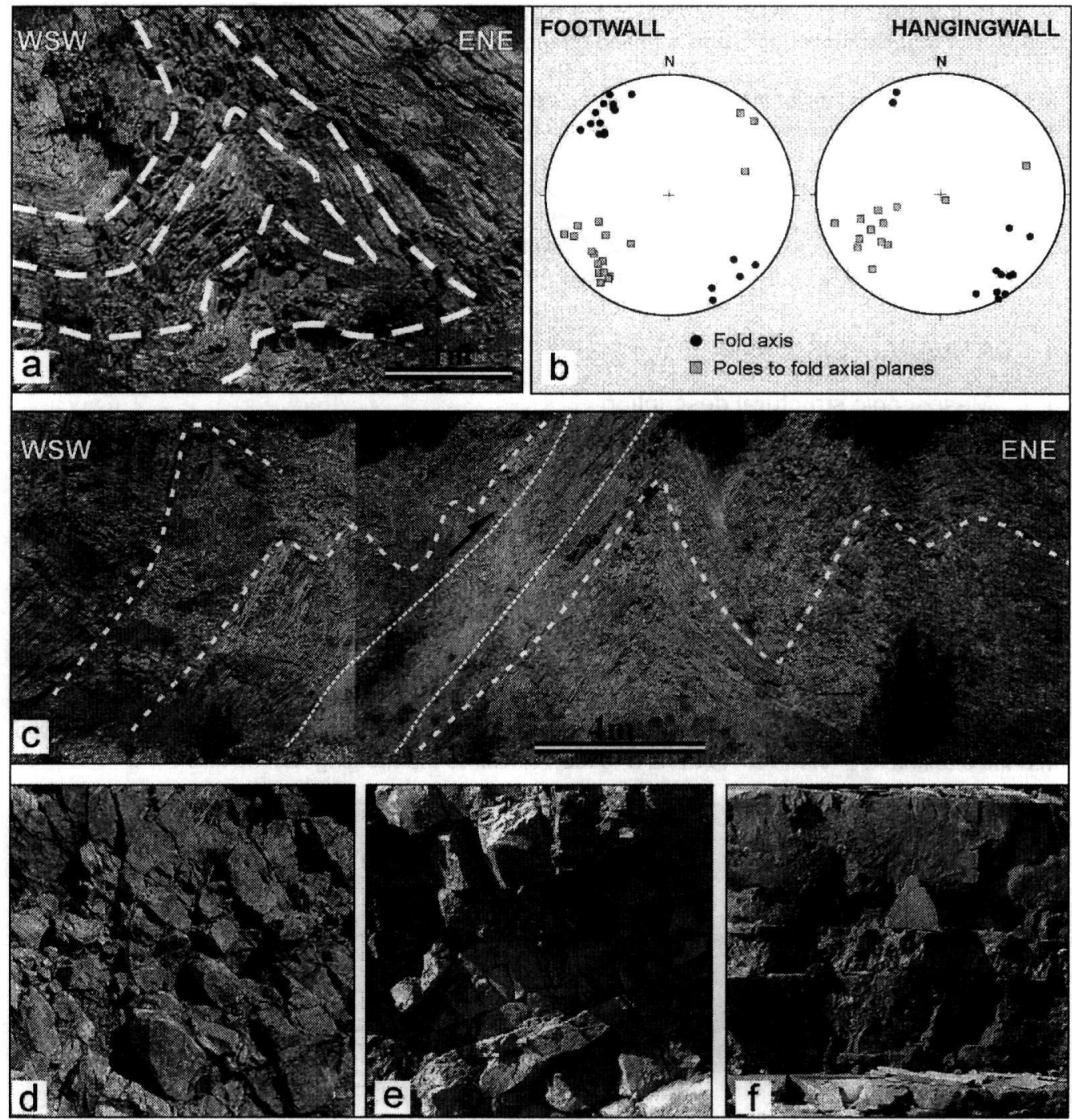

Figure 3. The most important observed structures along the cross-section and lower hemisphere equal area projections of fold orientation data. (a) Refolded Vigla limestone beds observed in hanging wall bellow a major subsidiary thrust fault indicate at least two major deformation events. See figure 2 for the location of photo (b) Stereonets of fold orientation data for both footwall and hanging wall. Folds in both sides of the Klimatia thrust display axis trending NNW-SSE. The majority of the folds show vergence towards WSW. (c) A west dipping bedding parallel shear zone at the west limb of a major anticline in the footwall of the Klimatia thrust fault. This structure supports backward movements (eastwards). See figure 2 for the location of photo. (d,e,f) Successive representative photographs showing the decrease of fracturing away from the thrust in hanging wall. (d) The photograph is taken close to Klimatia thrust fault and the wallrock is strongly deformed. (e) The photograph is taken in the middle of damage zone in the hanging-wall. Limestones here are less deformed. (f) Horizontal limestone beds near the end of the damage zone where the measured total fracture density values approach the background value. 


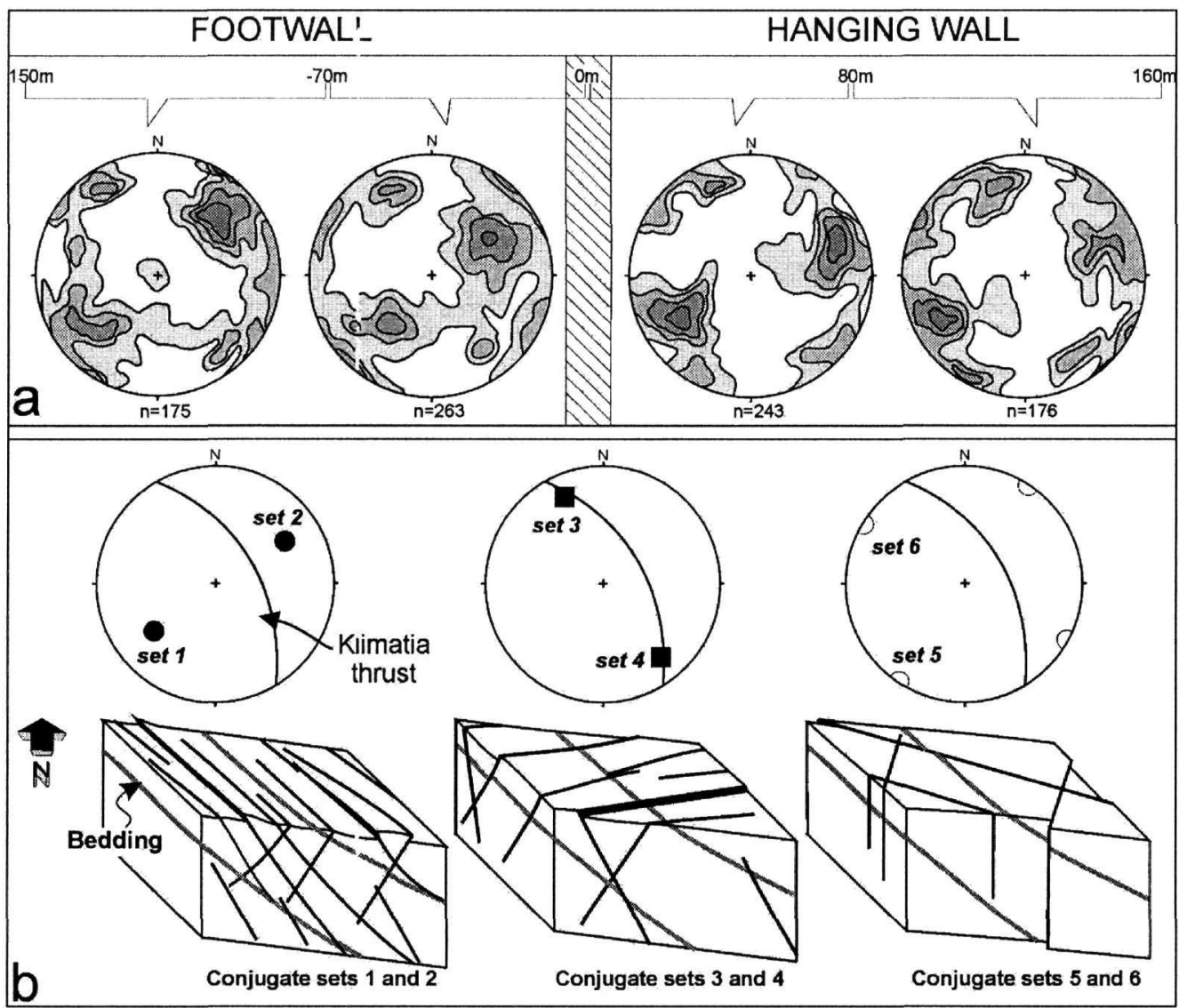

Figure 4. Stereonets (lower hemisphere equal area projections) of fracture orientation data and block diagrams of the identified fracture sets. (a) Four stereonets were produced in order to be compared for identifying the fracture sets participating in the overall fracturing. The comparison showed that there is a constant presence of six fracture sets throughout the fault zone. Contours are generally 1, 2, 3, 5 times uniform distribution (b) From the statistical analysis three systems of conjugate sets were identified. The first fracture system includes the NW- to NNW trending conjugate sets 1 and 2, trending parallel to Klimatia thrust. The second system includes the ENEtrending conjugate sets, 3 and 4 , which are almost perpendicular to Klimatia thrust fault and the third includes the WNW and NNE conjugate sets 5 and 6 with almost vertical dips.

\subsection{Fracture density measurements}

\subsubsection{Total Fracture density measurements}

Total FD values are projected on a diagram versus distance (Fig. 5a). Every point in this diagram represents the average FD values in $5 \mathrm{~m}$ intervals. The thick line expresses the total fracture density distribution and is normalized according to the least square theory by using the PeakFit software. At several distances more than $200 \mathrm{~m}$ away from the thrust to the east (e.g. $200 \mathrm{~m}, 500 \mathrm{~m}$, $1000 \mathrm{~m}, 1.500 \mathrm{~m}$ ), the total fracture density value was measured on horizontal beds. These values are generally constant ( $30 \pm 5$ fractures per meter) and therefore used as a background value. According to the diagram, in the hanging wall, the total fracture density decreases from $95 \mathrm{f} / \mathrm{m}$ close to thrust till it reaches the background value in a distance of $190 \mathrm{~m}$ away from it (Fig.3d, e, $f$ and $5 \mathrm{a}$ ). In the footwall total fracture den:sity values decrease from $90 \mathrm{f} / \mathrm{m}$ and reach the background value in a distance of $140 \mathrm{~m}$ away from the thrust. Therefore the estimated total damage zone width is $330 \mathrm{~m}$. Moreover, it should be noted that the observed decrease of FD away from the thrust is strongly irregular in both sides of the thrust. The comparison of FD distribution with the cross section showed that the peaks of the total fracture density-distance diagram coincides always with the position of 
the subsidiary thrust faults. We also infer that the total fracture density distribution reflect the heterogeneity of deformation in the damage zone, with pods of relatively undeformed rock (valleys) surrounded by strongly deformed anastomosing zones (peaks).

\subsubsection{Trigonometric corrected Fracture density measurements}

The trigonometric correction was applied for every one of the three already mentioned fracture systems and not for every set separately. In this case we measured normal to each system comprised by two conjugate sets by using an equation, which is based on the Terzaghi equation (1)

$$
N_{(1,2)}=N_{1(S L 0)}{ }^{*}\left(\operatorname{COS}\left(\theta_{1}\right) / \operatorname{COS}\left(\theta_{01}\right)+N_{2(S L 0)}{ }^{*} \operatorname{COS}\left(\theta_{2}\right) / \operatorname{COS}\left(\theta_{02}\right)(2)\right. \text {, }
$$

Where, $N_{(1,2)}$ is the number of fractures of conjugate sets 1 and 2 measured on a line normal to both fracture sets, $N_{1(S L O)}$ is the number of fractures of the set 1 measured along the outcrop scan line, $N_{2(S L O)}$ is the number of fractures of the set 2 measured along the outcrop scan line, $\theta_{1}$ is the angle between the normal to fracture set 1 and the normal to fracture sets 1 and $2, \theta_{2}$ is the angle between the normal to fracture set 2 and the normal to fracture sets 1 and $2, \theta_{01}$ is the angle between the outcrop scan line and the normal to fracture set 1 , and $\theta_{02}$ is the angle between the outcrop scan line and the normal to fracture set 2.

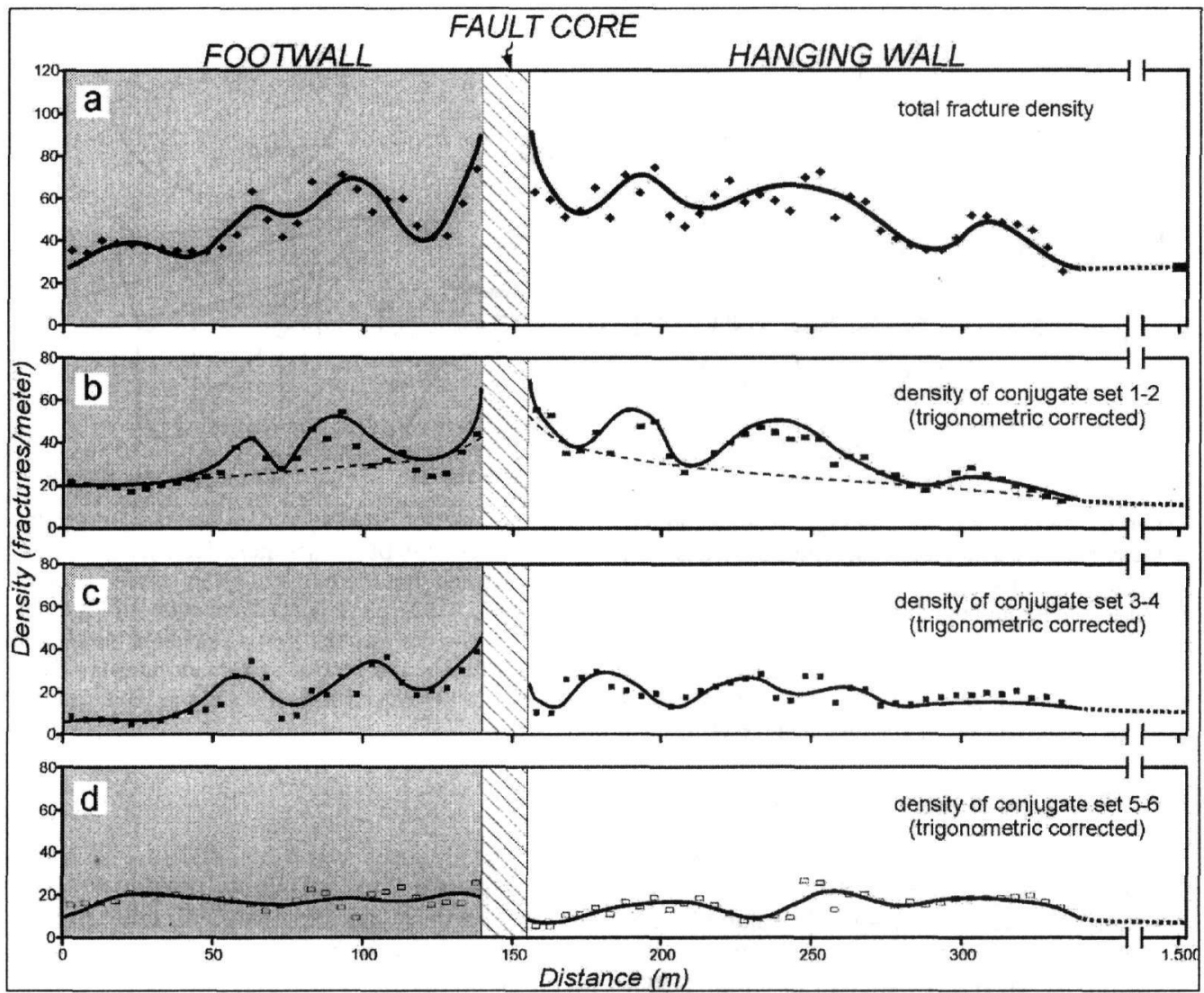

Figure 5. Resulted fracture density-distance diagrams. (a) Total fracture density decreases away from the thrust in both sides, in an irregular way. (b) The fracture density distribution of trigonometric corrected conjugate sets 1-2 (parallel to thrust) follows generally the total fracture density distribution. The minimum FD values lie on an asymptotic line (dashed line) (c) For the conjugate fracture sets 3-4 (perpendicular to thrust), the trigonometric corrected fracture density values are lower showing decrease away from the thrust in a less pronounced way. (c) The fracture density distribution is constant with low values for the conjugate sets 5-6.

The trigonometric corrected FD values of conjugate sets, 1-2, 3-4 and 5-6 were projected on density-distance diagrams (Fig. 5b, 5c, 5d) and are compared with the total fracture density distri- 
bution (Fig. 5a). The fracture density distribution of conjugate sets $1-2$, which are almost parallel to Klimatia thrust fault, follows the pattern of the total fracture density distribution with a general inhomogeneous decreasing trend away from the thrust (Fig. 5b). Moreover, remarkable is that all valleys of this distribution lie on an asymptotic line. For the conjugate fracture sets 3-4 which are trending almost perpendicular to Klimatia thrust, the fracture density values are lower in comparison to the previous system (Fig. 5c). Fracture density distribution of these sets shows a very slight increase toward the thrust. For the third system comprising the conjugate sets 5 and 6 the fracture density distribution is constani with low values throughout the scan line (Fig. 5c).

\subsection{Fracture spacing anklysis}

For $180 \mathrm{~m}$ along the scan line $(90 \mathrm{~m}$ in the hanging wall and $90 \mathrm{~m}$ in the footwall away from the thrust) we measured the spacing of every immediately adjacent fracture. From the total spacing estimation almost 9.000 segments were measured. Based on these measurements two fracture spacing histograms were constructed for each side of Klimatia thrust (Fig. 6). The fracture spacing for both hanging wall and footwall follows a negative exponential probability density distribution and there is a great similarity between the two diagrams.
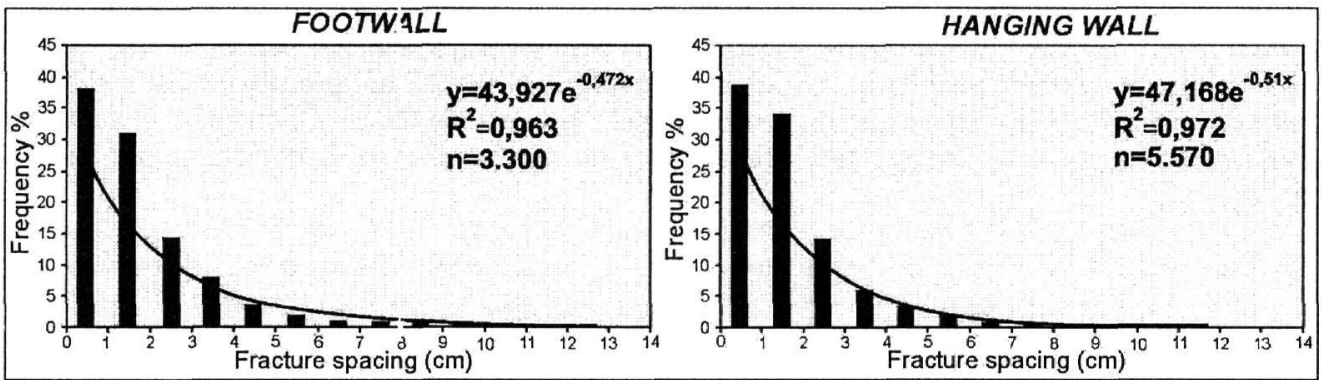

Figure 6. Fracture-spacing histograms. Fracture spacing follows negative exponential probability density distribution in both footwall and hanging wall.

\section{DISCUSSION AND CONCLUSIONS}

Our structural analysis showed significant variation in the style of deformation across the Klimatia thrust fault. Deformation in the footwall is mainly characterized by folding and a major zone of backthrusting. In the hanging wall, three splay thrust faults which are correlated genetically to refolding express the style of deformation. Given that the Klimatia thrust fault can be classified as a

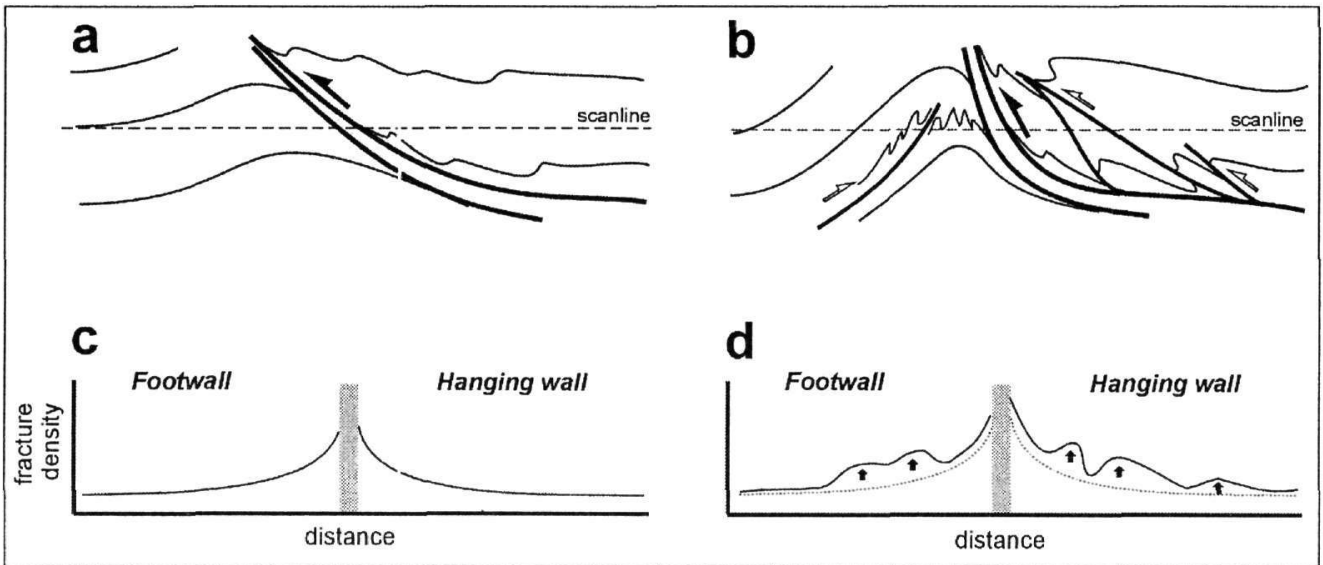

Figure 7. Summary model showing progressive deformation and associated structures correlated to the fracture density distribution. 
fault-related-fold structure (in the sense of Woodward et al., 1989) then it is safe to say that both folding and thrusting were active processes throughout the deformation. These observations enable us to distinguish at least two major deformation events during the progressive deformation in the Klimatia thrust fault zone (Fig. 7a, 7b). The first deformation stage includes the initiation of Klimatia thrust fault, layer parallel shearing and slight folding (Fig. 7a). The second deformation stage includes the formation of three splay thrust faults as break-back structures and refolding in the hanging wall, as well as fold tightening and backward shearing in the footwall (Fig. $7 \mathrm{~b}$ ). The age of these compressional movements cen not be directly estimated since syn-orogenic sediments are not observed in the footwall of the Klimatia thrust fault. Therefore, we assume that the studied contractional structures were developed at the Oligocene-Early Miocene time coeval with the major thrust faults of the Ionian zone.

Consequently, trying to correlate the structural evolution across the Klimatia thrust to the fracture density distribution we propose a possible model of two deformation stages, illustrated graphically in figure 7 . In the first stage, the fracture density decreases almost regularly away from the thrust (Fig. 7c). This assumption is mainly substantiated by two observations: (a) the minimum FD values on the fracture density diagram (bottom of valleys) of the dominant fracture system fit well on an asymptotic line which implies regular fracture density decrease away from the thrust (Figs. $5 \mathrm{~b}, 7 \mathrm{c}$ ) and (b) by the fact that the peaks of these diagrams always coincide with the position of the splay thrust faults which post-date the Klimatia thrust as well as with the position of the backthrust zone in the footwall (Fig. 7b, 7d). In the second stage, the formation of splay- and back- thrust faults cause the observed irregular and heterogeneous distribution of the fracture density across the Klimatia thrust.

Our study also showed that fracture sets that trend almost parallel to the thrust (conjugate sets 1,2 ; Figs. $4 b, 5 b$ ) are dominant. These are mainly associated with pressure solution cleavage and have the major participation in the overall fracturing. The fracture sets which are trending almost perpendicular to the thrust (conjugate sets 3,4 ; Fig. $4 \mathrm{~b}$ ) are associated mainly with normal sense shearing. This fracture system show a slight increasing density tendency towards the thrust fault with less participation in the overall fracturing (Fig. 5c). The diagonal fracture sets (conjugate sets $5,6)$ show constancy with the minor participation among the three fracture systems. Although, a detail discussion of the temporal evolution of these fracture systems is beyond the scope of this work, however, based on previous studies (e.g. Peacock 2001; Kokkalas et al. 2003; Olsson et al. 2004) we assume that all fracture sets formed during the progressive deformation in Klimatia thrust under the same compressional far-fi $\mathrm{fld}$ stress regime which caused the master fault.

From this study the main concluding remarks are summarized bellow.

(1) For the Klimatia thrust fault we estimated that the proportion, Displacement: Damage zone width: Fault core width, is approximately 50:25:1.

(2) The decrease of fracture density away from the thrust fault is heterogeneous and irregular in both hanging wall and footwall indicating a non-uniform distribution of deformation intensity.

(3) We consider that deformation intensity occurred within a progressive deformational process, which includes at least two major deformation events. Second order structures, which post-date Klimatia thrust formation, are responsible for the observed irregularity in the fracture density distribution.

(4) The dominant fracture sets trend parallel to the major thrust showing an increase tendency in frequency toward the fault. Sets perpendicular to the thrust show similar but less pronounced tendency.

(5) The fracture spacing for both hanging wall and footwall follows a negative exponential probability density distribution. From the mechanical point of view, this great similarity of these two diagrams probably implies that rucks in both sides of the thrust have the same response and behavior to the applied strain.

\section{REFERENCES}

Billi, A., Salvini, F., and Storti., F., 2003. The damage zone-fault core transition in carbonate rocks: implications for fault growth, structure and permeability, Journal of Structural Geology, 25, 1779-1794. 
Chester, F.M., and Logan, J.M., 1986. Implications for mechanical properties of brittle faulting observations of the Punchbowl fault zone, California. Pure and Applied Geophysics, 124, 79-106.

Du Bernard, X., Labaume, P., Darcel, C., Davy, P., and Bour, O., 2002. Cataclastic slip band distribution in normal fault damage zones, Nubian sandstones, Suez rift, Journal of Geophysical Research, 107 (B7), art.no. 2141.

Karakitsios, V., 1995. The influence of preexisting structure and halokinesis on organic-matter preservation and thrust system evolution in the Ionian basin, Northwest Greece, American Association of Petroleum Geologists Bulletin, 79, 960-980.

Kim, Y.-S., Andrews, J.R., and Sanderson, D.J., 2001a. Reactivated strike-slip faults: examples from north Cornwall, UK, Tectonophysics, 340, 173-194.

Kim, Y.-S., Andrews, J.R., and Sanderson, D.J., 2001b. Secondary faults and segment linkage in strike-slip fault systems at Rame Head, southern Cornwall, Geoscience in South-West England, 10, 123-133.

Kim, Y.-S., Peacock, D.C.P., and Sanderson, D.J., 2004. Fault damage zones, Journal of Structural Geology, 26, 503-517.

Kokkalas, S., Xypolias, P., Koukcuvelas, I., and Doutsos, T., 2003. Relationships between folding and fracturing in Orogenic belts: examples from the Rhenohercynian zone (Germany) and the External Hellenides (Greece), Geological Carpathica, 54, 153-162.

McGrath, A.G., and Davison, I., 1995. Damage zone geometry around fault tips, Journal of Structural Geology, 17, 1011-1024.

Micarelli, L., Moretti, I., and Daniel, J.M., 2003. Structural properties of rift-related normal faults: the case study of the Gulf of Corinth, Greece, Journal of Geodynamics, 36, 275-303.

Mitra, G., 1984. Brittle to ductile transition due to large strains along the White Rock thrust, Wind River Mountains, Wyoming, Journal of Structural Geology, 6, 51-61.

Mitra, G., 1992. Deformation of $g$ anitic basement rocks along fault zones at shallow to intermediate crustal levels. In Mitra, G., and Fisher, G.W., (eds), Structural Geology of Fold and Thrust Belts. Jonhs Hopkins Univercity Press, Baltimore, MD, 123-144.

Mitra, G., 1993. Deformation processes in brittle deformation zones in granitic basement rocks: a case study from the Torrey Creek area, Wind River Mountains. In Schmidt, C., Chase, R., and Erslev, E., (eds), Basement Behavior in Rocky Mountain Foreland Structure. Geological Society of America, Special Papers 280, 177-195.

Mitra, G., and Ismat, Z., 2001. Microfracturing associated with reactivated fault zones and shear zones: what can it tell us about deformation history? In R.E. Holdsworth, R.A. Strachan, J.F. Magloughlin, and R.J. Knipe (eds), The Nature and Tectoric Significance of Fault Zone Weakening. Geological Society, London, Special Publication 186, 113-140.

Newman, J., and Mitra, G., 1993.Lateral variations in mylonite zone thickness as influenced by fluid-rock interactions, Linville Falls Fault, North Carolina, Journal of Structural Geology, 15, 840-863.

Olsson, W.A., Lorenz, J.C., and Cooper, S.C., 2004. A mechanical model for multiply-oriented conjugate deformation bands, Journal of Structural Geology, 26, 325-338.

Peacock, D.C.P., 2001. The temporal relationship between joints and faults, Journal of Structural Geology, 23, 329-341.

Priest, S.D., 1993. Discontinuity analysis for rock engineering, London, Chapman \& Hall, 473pp.

Sibson, R.H., 1996. Structural permeability of fluid-driven fault-fracture meshes, Journal of Structural Geology, $18,1031-1042$

Terzaghi, R.D., 1965. Sources of error in joint surveys, Geotechnique, 15, 287-304.

Viruete, J.E., Carbonell, R., Jurado, M.J., Martí, D., and Pérez-Estaún, A., 2001. Two-dimensional geostatistical modeling and prediction of the fracture system in the Albala Granitic Pluton, SW Iberian Massif, Spain, Journal of Structural Geology, 23, 2011-2023

Yonkee, W.A., and Mitra, G., 1993. Comparison of basement deformation styles in the Rocky Mountain Foreland and Sevier Orogenic Belt. In Schmidt, C., Chase, R., and Erslev, E., (eds), Basement Behavior in Rocky Mountain Foreland Structure. Geological Society of America, Special Papers 280, 197-228.

Woodward, N.B., Boyer, S.E. and Suppe, J., 1989. Balanced geological cross-sections: An essential technique in geological research and exploration. Washington, American Geophysical Union, 132pp. 